\title{
Physical fitness and levels of physical activity in people with severe mental illness: a cross-sectional study
}

\author{
David Perez-Cruzado ${ }^{1,4}$, Antonio I. Cuesta-Vargas ${ }^{1,2,4^{*}}$, Elisa Vera-Garcia ${ }^{1,3}$ and Fermín Mayoral-Cleries ${ }^{3}$
}

\begin{abstract}
Background: Physical fitness is a crucial variable in people with severe mental illness as these people could be more independent and improve their job opportunities. The present study compared the physical fitness of physically active and inactive people with severe mental illness.

Methods: Physical fitness was evaluated in sixty-two people with severe mental illness using 11 physical tests that include strength, flexibility, balance and aerobic condition. Significant differences were found between both groups in muscle strength (handgrip test) and balance (single leg balance test and functional reach) with better performance in the group of physically active people.

Results: The results of the present study suggest that physical fitness (strength and balance) is higher in people with severe mental illness who practise regular physical activity that those who are inactive people.

Conclusions: Physical active people may have a reduced risk of falls and fractures due to their higher levels of physical fitness.
\end{abstract}

Keywords: Schizophrenia, Physical illness, Physical activity, Physical fitness, Psychiatry

\section{Background}

Severe mental illness (SMI) applies to all those people with functional psychosis over 18 who have an ICD-10 diagnosis of an affective or non-affective functional psychotic disorder (Codes F10-F22, F24, F25, F28-F31. F32.3, F33.3) [1]. People with SMI have a decrease of at least $20 \%$ in life expectancy due to premature death and the increase of cardiovascular disease [2, 3]. High levels of risk of death in this population reflects a combination of factors, such as the increased prevalence of different diseases, adverse effects of drug treatment or poor access to physical care and physical activity [4].

Physical activity provides significant health benefits to people with SMI, reducing the risk of many diseases of this population [5-7], representing an increase in job opportunities and greater independence in performing

* Correspondence: acuesta@uma.es

${ }^{1}$ Department of Physiotherapy, Faculty of Helath Sciences, University of

Malaga, Av/ Arquitecto Peñalosa s/n, Malaga, Spain

${ }^{2}$ School of Clinical Science, Faculty of Health Science, Queensland University

Technology, Brisbane, QLD, Australia

Full list of author information is available at the end of the article activities of daily living $[8,9]$, so that the participation of adults with severe mental illness in sports and recreational activities has often been addressed to enhance overall wellbeing and promote social inclusion [10-12].

Despite all the benefits provided by physical activity for people with SMI these people find many barriers to this physical activity leading them to lack motivation and selfefficacy for independent physical activity [13]. For instance, there is a lack of social support by professionals and family to practise physical activity and a lack of physical activity priority over other mental health treatments $[14,15]$, so this population is a group at risk of all negative consequences of a sedentary lifestyle $[16,17]$.

The aim of the present study is to determine the levels of physical fitness of people with SMI and identify any differences between their level of physical fitness and amount of physical activity.

\section{Methods \\ Participants}

In the present study, 62 people with SMI (37 men and 25 women) participated. They were aged between 26 and 
61 years, and recruited from the Hospital Civil, Malaga (Spain) between March and May of 2015. All participants were inpatients and had been diagnosed with a pathology included in SMI. Their general health was checked with a physical examination prior to participation of these people in the study. Participants included in the present study had not experienced exacerbation of their symptoms and were not suffering from any disease that limited them in physical activity or physical tests. Participants attended the Hospital Civil $4 \mathrm{~h}$ a day from Monday to Friday. The participants had all the rest of the day free to participate in activities that involve the practice of physical activity. The participants were independent people when deciding whether or not they wanted to perform physical activity.

Participants were asked about their adherence to physical activity, and the hours per week that they practised physical activity (30 min per day, moderate intensity) were recorded to divide the sample according to their physical activity level. Data about self-reported physical activity was ensured by staff and family members, since the information provided by the participants was contrasted by the information given by the relatives and the staff. There were no discrepancies between the information given by the participants and that granted by the workers and their families. Participants were identified as physically active or inactive according to physical activity engaged 3-7 days per week (active) or 1-2 days per week (inactive) [18].

\section{Study design and procedure}

A cross-sectional study was performed. Two examiners assessed the physical fitness in people with SMI with 11 physical tests to assess flexibility, strength, balance and aerobic condition. Physical tests were explained to participants and the examiners demonstrated how the test should be performed if they did not understand.

\section{Physical tests were}

Passive knee extension (PKE): Each participant is positioned supine on a stretcher with hip and knee flexed at 90 degrees. This test is evaluated with the aid of a goniometer. If the knee attains full extension, it is recorded as $0^{\circ}$, whereas if the extension fails to register, it has a negative value [19]. The reliability of the PKE test in this population is excellent (0.95-0.98) [20]. Calf muscle flexibility (CMF): The participant is placed supine on a stretcher, with hip and knee at the maximum extent possible. Each participant is asked to perform a dorsiflexion of the foot. If the participant cannot get to that position, the angle is recorded as negative, whereas if it goes beyond the neutral position, it is recorded as positive [21]. The reliability of this test in people with ID can be found in Waninge et al. $(0.86-0.93)$ [22].
Anterior hip flexibility (AHF): The participant is placed supine with both hips flexed at $90^{\circ}$. Measured hip is flexed to $100^{\circ}$ with one hand under the lower back to make sure it does not rise. Degrees of extension between the pelvis and thigh before the pelvis begins to move forward are measured. If the thigh extends down to the table, this is recorded as $0^{\circ}$, and if it does not extend to the table, the angle is recorded as negative [21]. Validity of this test can be found in "Brockport Physical Fitness Test Manual: A Health-Related Assessment for Youths with Physical and Mental Disabilities" [23]. Functional shoulder rotation (FSR): The participant is placed standing and should position the arm behind the head and back and the other arm behind the hip and back. The participant should try touching their index fingers, and the distance is measured with a tape. The distance is negative if they fail to touch their fingers and positive if contact is made. The upper arm defines the side to evaluate [24]. The reliability of this test can be found in Edwards et al. (2002) [25]. The time-stands test (TST): This test is used to evaluate the strength of the lower extremities. The participant must sit upon and rise from the chair 10 times, as fast as possible without using their arms. The time it takes the participant to complete the exercise is recorded [26]. The reliability of this test can be found in Newcomer et al. (1993) [26]. Partial sit-up test (PSUT): This test is used to measure abdominal strength. The participant must make the maximum possible number of abdominal contractions in a minute from a supine position with their legs placed on a chair or weight to maintain knee and hips flexed at $90^{\circ}$ [27]. Test-retest reliability and validity was established in a previous study [28].

Seated push-up (SPU): This test is used to evaluate the strength off triceps, shoulders and pectoral muscle. In this test, each participant must raise their body from a sitting position (with extended knees) until elbows are straight for $30 \mathrm{~s}$. The length of time they remain in this position is recorded [29]. Reliability and validity of the test are shown in the study of Graham \& Reid [30]. Handgrip test (HGT): This is a standardized method to assess the strength of the muscles of the hand and forearm. The arm must remain with the elbow bent at 90 degrees [31]. Reliability and validity of the test are shown in the study of Graham \& Reid [30]. Single leg stance (SLS): This test is used to evaluate static balance. The participant must stand on one leg for as long as possible. The second time that each participant remains in this position is recorded (maximum 60 s). The arms must remain on the hip with elbows slightly bent. The test is performed with each supported leg and with eyes open (EO) [32] and eyes closed (EC) [33]. Validity and reliability of both test can be found in the study of Lahtinen et al. [28]. 
Functional reach test (FRT): In this test, the participant must reach as far as possible without loss of balance. For this, the participants stand with feet should width apart, with arms bent at 90 degrees and extended fingers. In this position, participants lean forward and the maximum length reached is recorded in centimetres [34]. Test-retest reliability was established in the study of Cuesta-Vargas \& Gine-Garriga [35]. Two-minute step test (2MST): In this test, the participant is placed near a wall where the minimum height is marked to where legs must be raised. Each participant must perform a step-up in place for 2 minutes, lifting her legs to the level that appears on the wall. Heart rate is evaluated at rest, just after completion of the test and 2 minutes after finishing the test [36]. This test have been validated in people disabilities [37].

\section{Ethical issues}

The study was approval approved by the Ethics Committee of the University of Malaga and was carried out following the principles of the Declaration of Helsinki. At all times the anonymity of the participants was guaranteed according to the Data Protection Law.

Prior to participate in the study, an informed consent and a document with frequently asked questions were read by the participants. A written consent was obtained of all participants of the study.

\section{Statistical analysis}

Descriptive data for all variables were presented as mean and standard deviation. The normal distribution of data was assessed with the Kolmogorox-Smirnov test. Depending on the results of the test, a t-test or Wilconxon test was applied. Data analysis was performed with SPSS version 22.0 statistical software.

\section{Results}

In the present study, 62 people with SMI were evaluated and all participants completed all the physical tests with no missing data. No participants withdrew from the study or refused to perform any physical test. Of the 62 participants, $21(33.87 \%)$ were categorized as physically active because they engage in physical activity 3-7 days per week, while 41 participants (66.13\%) were categorized as physically inactive. The average height of the sample was $164.77( \pm 20.81)$ centimetres, and the average weight was 81.25 (15.84) kilogrammes, with a waist circumference of $103.04( \pm 13.53)$ centimetres and a BMI (body mass index) of $29.86( \pm 3.12)$, with no significant differences between the active and inactive participants. The average age of the sample was 46.21 ( \pm 8.37$)$ years with no significant differences neither.

Descriptive and inferential data about physical fitness are presented in Table 1. Significant differences were found between physically active group and physically inactive group in one strength test (handgrip test) and in balances tests (SLS with closed eyes and FRT with left leg.

Some physical tests such as hand strength (HGT) and balance tests (SLS and FRT) demonstrated that the group of active people had better performance than the group of inactive people. In contrast, As for the physical test that assessed flexibility and aerobic condition, significant differences were not found with the group of people physically inactive in spite of the group of active people had better performance in all assessed tests in flexibility, strength, balances and aerobic condition.

As for the physical test that assessed flexibility and aerobic condition, even though the group of active people had better performance in these tests, significant differences were not found with the group of people physically inactive.

\section{Discussion}

The present study explores the physical fitness of people with SMI and makes comparisons in relation to their levels of physical activity, To our knowledge, this study is the first to show the differences between the two groups of different levels of physical activity in people with SMI, and finds that there were significant differences in both the balance and the hand strength of people with SMI.

It is important to highlight the better performance in muscle strength and balance tests found in the group of physically active people, as these two variables (strength and balance) have been described as important predictors of serious public health problems, like risk of falls or sarcopenia $[38,39]$. Furthermore, it should be noted that physical activity in people with SMI is an important indicating factor for these people to have a better quality of life and be independent in carrying out the activities of daily life for as long as possible $[8,9,40]$. Moreover the improvement in physical fitness is one of the main reasons to engage in physical activity in this population [41].

Physical fitness in people with SMI has been measured in other studies $[42,43]$ with a different battery of physical tests, so the results of this study in terms of the physical tests used cannot be compared with similar studies. However, the study of Vancampfort et al. 2016 [43] in the Eurofit battery test used three physical tests similar to those used in the present study. Firstly, the SLS test with open eyes (physically active people $16.20 \pm 11.79$; inactive people $12.47 \pm 10.69$ ) found similar results to the study of Vancampfort et al., which used the Flamingo balance test $(16.75 \pm 9.00)$. Secondly, the HGT (physically active people $28.00 \pm 12.33$; inactive people $26.11 \pm 11.91$ ) obtained better performance in this test in Vancampfort et al. with a value of $40.55 \pm 11.75$. While for the abdominal strength test, the values of the present study were higher than those found in the study of Vancampfort et al., with a 
Table 1 T-student differences of the physical fitness test between both groups

\begin{tabular}{|c|c|c|c|c|}
\hline & & Physically active (mean \pm sd) & Physically inactive (mean $\pm \mathrm{sd}$ ) & Difference (student-t) \\
\hline \multirow[t]{8}{*}{ Flexibility } & Passive knee extension_right $\left({ }^{\circ}\right)$ & $-26.59( \pm 16.52)$ & $-24.18( \pm 13.84)$ & 0.39 \\
\hline & Passive knee extension_left $\left(^{\circ}\right)$ & $-22.95( \pm 17.79)$ & $-25.62( \pm 16.00)$ & 0.72 \\
\hline & Calf muscle flexibility_right $\left(^{\circ}\right)$ & $-0.95( \pm 3.19)$ & $-0.73( \pm 1.91)$ & -0.27 \\
\hline & Calf muscle flexibility _left $\left(^{\circ}\right)$ & $-1.95( \pm 5.52)$ & $-1.38( \pm 2.39)$ & -0.34 \\
\hline & Anterior hip flexibility_right $\left(^{\circ}\right)$ & $-0.44( \pm 2.08)$ & $0.03( \pm 1.13)$ & -0.92 \\
\hline & Anterior hip flexibility_left $\left(^{\circ}\right)$ & $-0.44( \pm 2.08)$ & $0.02( \pm 0.98)$ & -0.92 \\
\hline & Functional shoulder rotation_right $\left(^{\circ}\right)$ & $-14.18( \pm 15.39)$ & $-11.62( \pm 14.00)$ & -0.18 \\
\hline & Functional shoulder rotation_left $\left({ }^{\circ}\right)$ & $-20.15( \pm 14.5)$ & $-15.46( \pm 14.68)$ & -0.44 \\
\hline \multirow[t]{5}{*}{ Strenght } & Time-stands test (s) & $25.94( \pm 14.88)$ & $26.69( \pm 11.01)$ & -0.81 \\
\hline & Partial sit-up test (Repetition/1 m) & $25.79( \pm 12.47)$ & $26.20( \pm 8.87)$ & -0.34 \\
\hline & Seated push-up (s) & $15.11( \pm 7.60)$ & $15.26( \pm 10.80)$ & -0.57 \\
\hline & Handgrip test_right (kg) & $27.78( \pm 11.98)$ & $29.18( \pm 13.57)$ & $-0.22^{*}$ \\
\hline & Handgrip test_left (kg) & $24.44( \pm 11.84)$ & $26.83( \pm 11.09)$ & $0.53^{*}$ \\
\hline \multirow[t]{6}{*}{ Balance } & Single-leg stance_OE_right (s) & $14.39( \pm 11.97)$ & $15.68( \pm 12.09)$ & 0.18 \\
\hline & Single-leg stance_OE_left (s) & $10.58( \pm 9.41)$ & $16.73( \pm 11.47)$ & -2.04 \\
\hline & Single-leg stance_CE_right (s) & $5.29( \pm 6.95)$ & $10.30( \pm 8.27)$ & $-1.09^{*}$ \\
\hline & Single-leg stance_CE_left (s) & $3.74( \pm 5.06)$ & $10.53( \pm 10.14)$ & $-3.27^{*}$ \\
\hline & Functional reach test_right $(\mathrm{cm})$ & $32.55( \pm 10.97)$ & $38.34( \pm 7.82)$ & -1.60 \\
\hline & Functional reach test_left $(\mathrm{cm})$ & $30.96( \pm 10.06)$ & $40.21(10.61)$ & $-2.34^{*}$ \\
\hline \multirow[t]{3}{*}{ Aerobic Condition } & Two-minute step test_before (bpm) & $90.29( \pm 12.81)$ & $83.69( \pm 21.70)$ & 1.91 \\
\hline & Two-minute step test_after (bpm) & $112.63( \pm 19.50)$ & $105.31( \pm 19.19)$ & 0.35 \\
\hline & Two-minute step test_2min after (bpm) & $94.21( \pm 12.91)$ & $88.25( \pm 20.75)$ & 1.39 \\
\hline
\end{tabular}

$O E$ opened eyes, $C E$ : closed eyes

*: $p<0.05$

value of $15.11 \pm 7.60$ for physically active people and $15.26 \pm 10.80$ for inactive people against a value of $10.50 \pm$ 8.00 in the study of Vancampfort et al. Despite the differences in some physical tests between the present study and the study of Vancampfort et al., it is important to highlight that the participants were similar in terms of age $(46.21 \pm 8.37$ present study; $40.55 \pm 10.1$ study of Vancampfort et al.); whereas, the present study included a higher number of diseases listed as SMI, while the study of Vancampfort et al. included only people diagnosed with bipolar disorder and schizophrenia.

The differences in physical fitness between active and inactive people with severe mental illness have only been shown in the Vancampfort et al. study and in the present study, although these differences have been shown in another population as intellectual disability [44], Although in many studies have shown the benefits of physical activity in improving physical fitness in this population $[45,46]$.

The present study demonstrates the difference in physical fitness between people with SMI who practise physical activity and those who do not practise physical activity, showing better performance of physical fitness in physically active people. Different physical activity interventions were carried out in which there was shown an improved physical fitness in people with SMI [11, 47], however, these interventions should not just focus on aerobic activity but also on increasing the muscle strength and balance of people with SMI and also encourage these people to perform physical activity independently and to decrease the risk of falls similar to those carried out in other populations as elderly people [48].

This better values in physical fitness shown in the present study into both strength and balance suggests that physically active people with SMI also experience a lower risk of falls and fractures, which are common due to high doses of anti-psychosis drugs which cause a loss of balance in this population [49].

\section{Conclusions}

In conclusion, the present study is the first to show differences in physical fitness in people with SMI that practise physical activity and those who do not practise physical activity, showing a significant difference in both muscle strength and balance between both groups, with better performance found for physically active people; although the physical fitness of people with severe 
mental illness is not only identified by their level of physical activity, we must focus on the variables that improve the physical fitness of these people to carry out future interventions.

\section{Limitations}

The present study has a number of limitations. Due to the large number of diseases that are included as SMI, it was not possible to find enough people with the same disease to conduct the study. Additionally, we did not use a standardized physical activity assessment and future efforts should include assessments with established reliability. Finally, being a cross-sectional study, it was not possible to affirm a causal relationship. On the other hand, the present study evaluate the physical fitness in people with SMI according their level of physical activity and the large number of assessed physical tests allows us to determine the physical fitness of this population across a large set of variables but in the future the present results could be improve finding the differences between different pathologies included in severe mental illness.

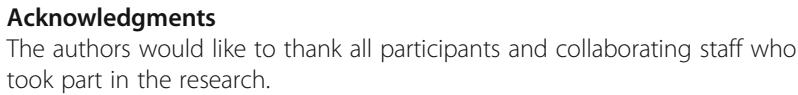

\section{Funding}

Role of funding source This research was partially funded by grants from OTRI-UMA (ref 806/423505-1) with a grant of part-time assistant research to David Perez-Cruzado.

\section{Availability of data and materials}

The datasets used and/or analysed during the current study are available from the corresponding author on reasonable request.

\section{Authors' contributions}

AICV has made contribution to conception of this study. EVC and FMC participated in the collect of data. AICV, DPC participated in the analysis and interpretation of data and were involved in drafting the manuscript or revising it critically for important intellectual content. All the authors have given final approval of the version to be published.

\section{Competing interest}

The authors state that no conflicts of interest have been reported by the authors or by any individual in control of the content of this article. This information has not been presented previously.

\section{Ethics approval and consent to participate}

The institutional review committee at the University of Malaga approved the procedures used in this study and ethical recommendations were taken into consideration at all stages during the research. The study complied with the principles laid out in the Declaration of Helsinki. Written consent was obtained from all participants of the study.

\section{Consent for publication}

Not applicable

\section{Publisher's Note}

Springer Nature remains neutral with regard to jurisdictional claims in published maps and institutional affiliations.

\section{Author details}

'Department of Physiotherapy, Faculty of Helath Sciences, University of Malaga, Av/ Arquitecto Peñalosa s/n, Malaga, Spain. ${ }^{2}$ School of Clinical Science, Faculty of Health Science, Queensland University Technology, Brisbane, QLD, Australia. ${ }^{3}$ Mental Health Research Group of Biomedicine Research Institute of Malaga (IBIMA) Spain, Regional University Hospital, Malaga, Spain. ${ }^{4}$ Clinimetric Research Group of Biomedicine Research Institute of Malaga (IBIMA) Spain, Regional University Hospital, Málaga, Spain.

Received: 5 April 2017 Accepted: 17 November 2017

Published online: 25 November 2017

\section{References}

1. Ruggeri M, Leese M, Thornicroft G, Bisoffi G, Tansella M. Definition and prevalence of severe and persistent mental illness. Br J Psychiatry J Ment Sci. 2000;177:149-55

2. Holmemo HD-Q, Fløvig JC, Heggelund J, Vedul-Kjelsås E. Differences in aerobic fitness between inpatients and outpatients with severe mental disorders. Front Psychiatry. 2014;5:95. doi: 10.3389/fpsyt.2014.00095.

3. Ösby U, Westman J, Hällgren J, Gissler M. Mortality trends in cardiovascular causes in schizophrenia, bipolar and unipolar mood disorder in Sweden 1987-2010. Eur J Pub Health January 2016. doi:10.1093/eurpub/ckv245.

4. Thornicroft G. Physical health disparities and mental illness: the scandal of premature mortality. Br J Psychiatry J Ment Sci. 2011;199(6):441-2. doi: 10. 1192/bjp.bp.111.092718.

5. Krogh J, Speyer H, Nørgaard HCB, Moltke A, Nordentoft M. Can exercise increase fitness and reduce weight in patients with schizophrenia and depression? Front Psychiatry. 2014;5:89. doi: 10.3389/fpsyt.2014.00089.

6. Vancampfort D, Probst M, Scheewe T, et al. Relationships between physical fitness, physical activity, smoking and metabolic and mental health parameters in people with schizophrenia. Psychiatry Res. 2013;207(1-2):25-32. doi: 10. 1016/j.psychres.2012.09.026.

7. Vancampfort D, Rosenbaum S, Ward PB, Stubbs B. Exercise improves cardiorespiratory fitness in people with schizophrenia: a systematic review and meta-analysis. Schizophr Res. 2015;169(1-3):453-7. doi: 10.1016/..schres.2015.09.029.

8. Chuang W-F, Hwang E, Lee H-L, Wu S-L. An in-house prevocational training program for newly discharged psychiatric inpatients: exploring its employment outcomes and the predictive factors. Occup Ther Int. 2015; 22(2):94-103. doi: 10.1002/oti.1388.

9. Conradsson M, Littbrand H, Boström G, Lindelöf N, Gustafson Y, Rosendahl E. Is a change in functional capacity or dependency in activities of daily living associated with a change in mental health among older people living in residential care facilities? Clin Interv Aging. 2013:8:1561-8. doi: 10.2147/CIA.S53270.

10. Gross J, Vancampfort D, Stubbs B, Gorczynski P, Soundy A. A narrative synthesis investigating the use and value of social support to promote physical activity among individuals with schizophrenia. Disabil Rehabil. 2016; 38(2):123-50. doi:10.3109/09638288.2015.1024343.

11. Vera-Garcia E, Mayoral-Cleries F, Vancampfort D, Stubbs B, Cuesta-Vargas Al. A systematic review of the benefits of physical therapy within a multidisciplinary care approach for people with schizophrenia: an update. Psychiatry Res. 2015;229(3):828-39. doi: 10.1016/j.psychres.2015.07.083.

12. Firth J, Carney R, Jerome L, Elliott R, French P, Yung AR. The effects and determinants of exercise participation in first-episode psychosis: a qualitative study. BMC Psychiatry. 2016;16:36. doi: 10.1186/s12888-016-0751-7.

13. Vancampfort D, Knapen J, Probst M, Scheewe T, Remans S, De Hert M. A systematic review of correlates of physical activity in patients with schizophrenia. Acta Psychiatr Scand. 2012;125(5):352-62. doi:10.1111/j.1600-0447.2011.01814.x.

14. Rastad C, Martin C, Asenlöf P. Barriers, benefits, and strategies for physical activity in patients with schizophrenia. Phys Ther. 2014;94(10):1467-79. doi: 10.2522/ptj.20120443.

15. Soundy A, Stubbs B, Probst M, Hemmings L, Vancampfort D. Barriers to and facilitators of physical activity among persons with schizophrenia: a survey of physical therapists. Psychiatr Serv Wash DC. 2014;65(5):693-6. doi:10.1176/ appi.ps.201300276.

16. Schuch F, Vancampfort D, Firth J, et al. Physical activity and sedentary behavior in people with major depressive disorder: a systematic review and meta-analysis. J Affect Disord. 2017;210:139-50. doi: 10.1016/j.jad.2016.10.050.

17. Stubbs B, Firth J, Berry A, et al. How much physical activity do people with schizophrenia engage in? A systematic review, comparative meta-analysis and meta-regression. Schizophr Res. 2016;176(2-3):431-40. doi: 10.1016/j. schres.2016.05.017 
18. Daumit GL, Goldberg RW, Anthony C, et al. Physical activity patterns in adults with severe mental illness. J Nerv Ment Dis. 2005;193(10):641-6.

19. Gajdosik RL, Rieck MA, Sullivan DK, Wightman SE. Comparison of four clinical tests for assessing hamstring muscle length. J Orthop Sports Phys Ther. 1993;18(5):614-8. doi: 10.2519/jospt.1993.18.5.614.

20. Lee GP, Ng GY. Effects of stretching and heat treatment on hamstring extensibility in children with severe mental retardation and hypertonia. Clin Rehabil. 2008;22(9):771-9. doi: 10.1177/0269215508090067.

21. Ekstrand J, Wiktorsson M, Oberg B, Gillquist J. Lower extremity goniometric measurements: a study to determine their reliability. Arch Phys Med Rehabil. 1982;63(4):171-5.

22. Waninge A, Rook RA, Dijkhuizen A, Gielen E, van der Schans CP. Feasibility, test-retest reliability, and interrater reliability of the modified Ashworth scale and modified Tardieu scale in persons with profound intellectual and multiple disabilities. Res Dev Disabil. 2011;32(2):613-20. doi: 10.1016/j.ridd. 2010.12.013

23. Winnick JP, Short FX. The Brockport Physical Fitness Test Manual. Human Kinetics; 1999

24. Boström C, Harms-Ringdahl K, Nordemar R. Clinical reliability of shoulder function assessment in patients with rheumatoid arthritis. Scand J Rheumatol. 1991;20(1):36-48.

25. Edwards TB, Bostick RD, Greene CC, Baratta RV, Drez D. Interobserver and intraobserver reliability of the measurement of shoulder internal rotation by vertebral level. J Shoulder Elb Surg Am Shoulder Elb Surg Al. 2002;11(1):40-2. doi: 10.1067/mse.2002.119853.

26. Newcomer KL, Krug HE, Mahowald ML. Validity and reliability of the timedstands test for patients with rheumatoid arthritis and other chronic diseases. J Rheumatol. 1993;20(1):21-7.

27. Knudson D. The validity of recent curl-up tests in young adults. J Strength Cond Res Natl Strength Cond Assoc. 2001;15(1):81-5.

28. Lahtinen U, Rintala P, Malin A. Physical performance of individuals with intellectual disability: a 30 year follow up. Adapt Phys Act Q APAQ. 2007; 24(2):125-43.

29. Wood HM, Baumgartner TA. Objectivity, reliability, and validity of the bentknee push-up for college-age women. Meas Phys Educ Exerc Sci. 2004;8(4): 203-12. doi: 10.1207/s15327841mpee0804_2.

30. Graham A, Reid G. Physical fitness of adults with an intellectual disability: a 13-year follow-up study. Res Q Exerc Sport. 2000;71(2):152-61. doi: 10.1080/ 02701367.2000.10608893.

31. Bellace JV, Healy D, Besser MP, Byron T, Hohman L. Validity of the Dexter evaluation System's Jamar dynamometer attachment for assessment of hand grip strength in a normal population. J Hand Ther Off J Am Soc Hand Ther. 2000;13(1):46-51.

32. Birmingham TB. Test-retest reliability of lower extremity functional instability measures. Clin J Sport Med Off J Can Acad Sport Med. 2000;10(4):264-8.

33. Springer BA, Marin R, Cyhan T, Roberts H, Gill NW. Normative values for the unipedal stance test with eyes open and closed. J Geriatr Phys Ther 2001. 2007;30(1):8-15.

34. Duncan PW, Weiner DK, Chandler J, Studenski S. Functional reach: a new clinical measure of balance. J Gerontol. 1990;45(6):M192-7.

35. Cuesta-Vargas A, Giné-Garriga M. Development of a new index of balance in adults with intellectual and developmental disabilities. PLoS One. 2014; 9(5):e96529. doi: 10.1371/journal.pone.0096529.

36. Buckley JP, Sim J, Eston RG, Hession R, Fox R. Reliability and validity of measures taken during the Chester step test to predict aerobic power and to prescribe aerobic exercise. Br J Sports Med. 2004;38(2):197-205.

37. Bruni A, College U. Validity \& Reliability of the Two-Minute Step Test for Children and Adolescents with Intellectual Disabilities. Utica College; 2010.

38. Bullo $V$, Bergamin M, Gobbo $S$, et al. The effects of Pilates exercise training on physical fitness and wellbeing in the elderly: a systematic review for future exercise prescription. Prev Med. 2015;75:1-11. doi: 10.1016/j.ypmed. 2015.03.002

39. Schreier MM, Bauer U, Osterbrink J, Niebauer J, Iglseder B, Reiss J. Fitness training for the old and frail : effectiveness and impact on daily life coping and self-care abilities. Z Gerontol Geriatr. 2016;49(2):107-14. doi: 10.1007/ s00391-015-0966-0.

40. Gray M, Glenn JM, Binns A. Predicting sarcopenia from functional measures among community-dwelling older adults. Age Dordr Neth. 2016;38(1):22 doi: 10.1007/s11357-016-9887-0
41. Firth J, Rosenbaum S, Stubbs B, Vancampfort D, Carney R, Yung AR. Preferences and motivations for exercise in early psychosis. Acta Psychiatr Scand. 2016;134(1):83-4. doi: 10.1111/acps.12562.

42. Vancampfort D, Guelinckx H, Probst M, et al. Health-related quality of life and aerobic fitness in people with schizophrenia. Int J Ment Health Nurs. 2015;24(5):394-402. doi: 10.1111/inm.12145.

43. Vancampfort D, Stubbs B, Sienaert $P$, et al. A comparison of physical fitness in patients with bipolar disorder, schizophrenia and healthy controls. Disabil Rehabil. January 2016:1-5. doi: 10.3109/09638288.2015.1114037.

44. Cuesta-Vargas Al, Paz-Lourido B, Rodriguez A. Physical fitness profile in adults with intellectual disabilities: differences between levels of sport practice. Res Dev Disabil. 2011;32(2):788-94. doi: 10.1016/j.ridd.2010.10.023.

45. Ruegsegger GN, Booth FW. Health benefits of exercise. Cold Spring Harb Perspect Med. May 2017; https://doi.org/10.1101/cshperspect.a029694.

46. Hearon BA, Beard C, Kopeski LM, Smits JAJ, Otto MW, Björgvinsson T. Attending to Timely Contingencies: Promoting Physical Activity Uptake Among Adults with Serious Mental Illness with an Exercise-For-Mood vs. an Exercise-For-Fitness Prescription. Behav Med Wash DC. December 2016:1-8. doi:10.1080/08964289.2016.1276428.

47. Vancampfort D, Stubbs B, Probst M, et al. Physical activity as a vital sign in patients with schizophrenia: evidence and clinical recommendations. Schizophr Res. 2016;170(2-3):336-40. doi: 10.1016/j.schres.2016.01.001.

48. Duray M, Genç A. The relationship between physical fitness and falling risk and fear of falling in community-dwelling elderly people with different physical activity levels. Turk J Med Sci. 2017;47(2):455-62. doi: 10.3906/sag-1511-101.

49. Oderda LH, Young JR, Asche CV, Pepper GA. Psychotropic-related hip fractures: meta-analysis of first-generation and second-generation antidepressant and antipsychotic drugs. Ann Pharmacother. 2012;46(7-8): 917-28. doi: 10.1345/aph.1Q589.

\section{Submit your next manuscript to BioMed Central and we will help you at every step:}

- We accept pre-submission inquiries

- Our selector tool helps you to find the most relevant journal

- We provide round the clock customer support

- Convenient online submission

- Thorough peer review

- Inclusion in PubMed and all major indexing services

- Maximum visibility for your research

Submit your manuscript at www.biomedcentral.com/submit
) Biomed Central 